Published in final edited form as:

BJOG. 2018 February ; 125(3): 336-341. doi:10.1111/1471-0528.14522.

\title{
Offspring birth weight by gestational age and parental cardiovascular mortality: a population-based cohort study
}

\author{
N-H Morken ${ }^{a, b, c}$, F Halland $^{a, c}$, LA DeRoo $^{a, d}$, AJ Wilcox $^{d}$, and R Skjærven ${ }^{a, e, f}$ \\ aDepartment of Global Public Health and Primary Care, University of Bergen, Norway

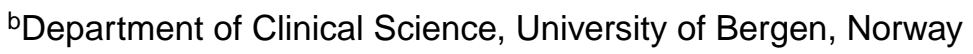 \\ 'Department of Obstetrics \& Gynecology, Haukeland University Hospital, Bergen, Norway \\ dEpidemiology Branch, NIEHS/NIH, Durham, North Carolina, USA \\ eMedical Birth Registry of Norway, Bergen, Norway \\ fNorwegian Institute of Public Health, Bergen, Norway
}

\section{Abstract}

Objective-To estimate risk of parental cardiovascular disease mortality by offspring birth weight.

Design-Population-based cohort study.

Setting and population-Norwegian mothers and fathers with singleton births during 19672002 were followed until 2009 by linkage to the Norwegian cause of death registry.

Methods-Hazard ratios (HR) by offspring absolute birth weight in gram and birthweight adjusted for gestational age (z-score) were calculated using Cox-regression and adjusted for parental age at delivery and year of first birth. Stratified analyses on preterm and term births were performed.

Main outcome measures-Maternal and paternal cardiovascular mortality.

Results-We followed 711726 mothers and 700212 fathers and found a strong link between maternal cardiovascular mortality and offspring birth weight but only slight evidence of associations in fathers. Adjusting birth weight for gestational age (by z-score) uncovered an unexpected strong association of large birth weight (z-score $>2.5$ ) with mothers cardiovascular mortality (HR: 3.0, 95\% CI: 2.0-4.6). This risk was apparently restricted to preterm births. In

Correspondence: N-H Morken, Department of Global Public Health and Primary Care, University of Bergen, Kalfarveien 31, 5018 Bergen, Norway, Cell phone 047922571 14, nils-halvdan.morken@uib.no.

Disclosure of interests: There are no conflicts of interest, including specific financial interests and relationships and affiliations relevant to the subject of this article.

Contribution to authorship: All researchers had full access to all of the data in the study and take full responsibility for the integrity of the data and the accuracy of the data analysis. NHM, FH and RS designed and proposed the study. NHM, FH and RS did the data analysis. NHM drafted the manuscript. LAD, FH, AJW and RS reviewed the preliminary analyses and the initial draft of the manuscript and provided critical comments. RS is guarantor for data quality.

Details of ethics approval: This study was approved by the internal review board of the Medical Birth Registry of Norway and by the regional ethics committee, REK Vest, Norway (reference number: 2009/1868, approved January $24^{\text {th }} 2011$ ). 
stratified analyses (preterm and term births) HR for maternal cardiovascular mortality was 1.5 (1.03-2.2) for large preterm babies and $0.9(0.7-1.2)$ for large term babies (p-value for interaction $=0.02$ ), using normal weight preterm and term, respectively as references.

Conclusion-Women having large preterm babies are at increased risk of both diabetes and cardiovascular mortality. The birth of a large preterm baby should increase clinical vigilance for onset of diabetes and other cardiovascular-disease risk factors.

\section{Keywords}

Offspring birth weight; cardiovascular mortality; diabetes

\section{Introduction}

Cardiovascular disease is an important cause of death in females. Globally, 1 of 3 women dies from cardiovascular disease ${ }^{1}$ and the awareness of heart disease as the leading killer in women has increased during the last decades. ${ }^{2}$

Predicting cardiovascular disease in women is difficult and the clinical presentation of the disease is often different in women compared to men. ${ }^{1,3,4}$ Pregnancy has been proposed as a physiological "stress-test" whereby a women's physiological response under the demands in pregnancy can predict long-term risk of disease. ${ }^{5}$ If so, pregnancy complications may enable early identification of high-risk women who would benefit from preventive intervention. ${ }^{6}$

Offspring low birth weight is a well-established predictor of parental cardiovascular disease and death. ${ }^{1,7-13}$ Maternal cardiovascular disease risk is highest with smaller babies, and declines by $25 \%$ with each standard-deviation increase (about $500 \mathrm{~g}$ ) in birth weight of the first child ${ }^{7}$ with similar but weaker association among fathers. The causal pathway is not clear, and may reflect both environmental and genetic influences. Additionally, this inverse association of offspring birth weight with parental mortality may not extend across the full range of birth weight. ${ }^{1}$

We assessed the risk of parental cardiovascular disease mortality by birth weight of offspring's, using linked data from population based registries of birth and mortality in Norway, covering up to 42 years of observation. We further refined the analysis by taking gestational age into account.

\section{Methods}

The Medical Birth Registry of Norway has collected data since 1967 on all live and stillbirths from 16 weeks of gestation. Records in the registry are matched with the files of the Central Person Register, to ensure medical notification of every newborn ${ }^{14}$, and to collect dates of deaths. Personal identification numbers are given to every Norwegian citizen. We used these identification numbers to link fathers and mothers to their offspring, and to link parents to the Cause of Death Registry. 
We included all firstborn singleton infants (of Norwegian origin) born during 1967 to 2002, and followed their parents through 2009 for death due to cardiovascular causes.

Maternal and paternal causes of death were classified according to the International Classification of Diseases (ICD) (ICD-8 for 1969-85, ICD-9 for 1986-95 and ICD-10 for the years 1996-2009). We combined deaths due to ischemic heart diseases, (I20-I25 [ICD-10], 410-414 [ICD-8 and ICD-9]) and cerebrovascular diseases/stroke (I60-I69 [ICD-10], 430-438 [ICD-8 and ICD-9]) into one entity ("cardiovascular deaths") as our main outcome variable.

Offspring birth weight was categorized into eight groups (500-999g, 1000-1499g, 15001999g, 2000-2499g, 2500-2999g, 3000-3499g, 3500-3999g and $\geq 4000 \mathrm{~g}$ ). Hazard ratios (HRs) for mothers' and fathers' cardiovascular mortality were estimated for each birth weight category, using 3000-3499g as reference level. We used offspring birth weight as a continuous variable for estimating HRs separately for birth weights above and below 3500 grams (assuming a non-linear relation across birth weights). We then adjusted birth weight for gestational age by converting offspring birth weight into z-scores at each gestational week. All births with z-scores below -4 and above 4 were excluded from analyses as likely errors. Z-scores were categorized as -4 to $-2.5,-2.5$ to $-1.5,-1.5$ to $-1,-0.5$ to $-0.5,-0.5$ to $0.5,0.5$ to 1,1 to $1.5,1.5$ to 2.5 and 2.5 to 4 . HRs for parental cardiovascular death were estimated for each z-score category, using z-score 1 to 1.5 as reference level.

We explored possible interactions between gestational age and birth size by examining statistical significance of interaction terms. Births were stratified into preterm ( 22 weeks to 36 weeks) and term births ( $>37$ weeks), and grouped by gestational-age specific z-score weights into three categories: small $(<-1.5)$, average $(-1.5$ to 1.5$)$ and large $(>1.5)$. HRs for cardiovascular mortality were estimated separately for preterm and term births, using one shared reference level (term births with z-score -1.5 to 1.5 ) to retain the different baseline levels of maternal mortality for preterm and term births. For women with two or more pregnancies, we also estimated the odds ratio (OR) of having diabetes in the second pregnancy, stratified on gestational age of the first infant (preterm and term) and by z-score category of the first offspring (as above).

We extended the analysis by considering parents with two heavy babies (defined as larger than the mean) in their first two pregnancies. We considered heavy weights in two categories: large ( $>0$ to 2.5 ) and very large (z-score $>2.5$ ). Families with two heavy babies were grouped as follows: both babies very large, first baby very large and the second large, first baby large and the second very large, and both babies large (reference category).

HRs for parental cardiovascular mortality were calculated using Cox proportional hazard models (SPSS, version 22.0), adjusting for year of birth and parental age (categorical variable: <20 years, 20-24 years, 25-29 years, 30-34 years and >35 years). Additional adjustment for level of education had no effect on the estimates and was not included in the final models. The time variable in the Cox models was time from first birth to either death or censoring, whatever occurred first. Odds ratios (ORs) for diabetes in the second pregnancy 
were calculated using logistic regression (SPSS, version 22.0), adjusting for year of birth of the second child and maternal age at birth of the second child.

This study was approved by the internal review board of the Medical Birth Registry of Norway and by the regional ethics committee, REK Vest, Norway (reference number: 2009/1868).

\section{Results}

Baseline characteristics of the study sample are outlined in the supporting information Table S1. There were 711726 mothers and 700212 fathers included in the analysis, of whom 2279 mothers $(0.3 \%)$ and 10163 fathers $(1.5 \%)$ died from cardiovascular causes during follow-up. Missing information was rare in mothers $(7,<0.00 \%)$ but not fathers (11 521, $1.6 \%$ ), due mainly to missing information on fathers among unmarried couples. This left slightly fewer fathers for analysis.

Figure 1 shows HRs for cardiovascular mortality for mothers and fathers by absolute birth weight of the first offspring. Lower birth weights were strongly associated with maternal cardiovascular mortality (HR: 3.6, 95\%CI: $2.8-4.6$ at 1000-1499g). The association was much weaker for fathers (HR 1.3, 95\%CI: 1.2-1.4 at 1500-1999g). There is no apparent association with heavy absolute birth weights.

We assessed the trends of reduced cardiovascular mortality per 500g increase in absolute birth weight (one standard deviation is approximately 500g). Trends were assessed separately below and above $3500 \mathrm{~g}$. For every $500 \mathrm{~g}$ of birth weight up to $3500 \mathrm{~g}$, the hazard of maternal cardiovascular death decreased by $25 \%$ (HR: $0.75,95 \%$ CI: $0.71-0.78$, p-trend: $<0.0001$ ). There was no further increase in cardiovascular mortality above $3500 \mathrm{~g}$ (HR: 0.96, 95\%CI: $0.85-1.10$, p-trend $=0.57$ ). For fathers, there was slightly improved cardiovascular mortality risk with increasing birth weights up to $3500 \mathrm{~g}$ (HR: 0.94, 95\% CI: 0.91-0.96, ptrend: <0.0001), and none above 3500g $(0.99,95 \% \mathrm{CI}$ : 0.94-1.05, p-trend $=0.70)$.

Women who deliver preterm are at higher risk of cardiovascular mortality. ${ }^{13,15}$ Thus, preterm delivery could be confounding the observed relation between offspring birth weight and mother's cardiovascular mortality risk. We therefore adjusted birth weight for gestational age by expressing birth weight in z-scores at each gestational week (Figure 2). The association of offspring's low birth weights with mother's cardiovascular mortality became log-linear, and an unexpectedly strong association of very large birth weights (zscore >2.5) with mother's cardiovascular mortality emerged (HR 3.0, 95\%CI: 2.0-4.6).

We further stratified these analyses on total number of lifetime pregnancies (one or 2+), using the z-score 1 to 1.5 within each stratum as reference. Women having one lifetime pregnancy are an established risk group for cardiovascular death later in life. ${ }^{16,17}$ In our data, these women had a 2.5 fold risk of cardiovascular death compared with women with 2 or more births. Risk patterns were similar by z-score birth weights in both strata. In mothers with only one lifetime pregnancy and a very large baby the HR was 2.6 (95\%CI: 1.4-5.1). With two or more pregnancies and a very large baby in the first, the HR was 3.0 (95\%CI: 
1.8-5.2). The same adjustments for gestational age had no effect on father's cardiovascular mortality (Figure 2).

We explored this unexpected association in mothers by stratifying the analysis by preterm and term (Figure 3). A striking interaction emerged: very large term babies had no adverse association with mother's cardiovascular mortality (HR: 0.9, 95\%CI: 0.7-1.2), while very large preterm babies were associated with higher cardiovascular mortality (HR: 1.5, 95\% CI: $1.03-2.2$; $\mathrm{p}$-value for interaction $=0.02)$. When using a single reference for both groups $(\mathrm{z}-$ score -1.5 to 1.5 for all births), mothers' HR for cardiovascular mortality with large babies was 3.8 (95\% CI: 2.3-6.3) with preterm babies, but null with term babies $(0.9,95 \%$ CI: $0.7-$ 1.2). In additional analyses we adjusted the results by maternal level of education; these patterns did not change.

One possibility for the high maternal cardiovascular mortality risk after birth of a large preterm baby could be the presence of maternal conditions, such as diabetes, that predispose for both heavy fetuses and preterm delivery, and also increase the mother's later cardiovascular disease risk. We explored this possibility in a sub-analysis in women having more than one birth by calculating the risk that mothers with a large first birth will develop diabetes in her next pregnancy (Figure 4). There was a marked increase in risk of diabetes after large babies (z-score >1.5), regardless of whether the first pregnancy was term or preterm.

We considered the association of repeated large babies on later maternal cardiovascular mortality. The HR for cardiovascular death in women having two very large babies (z-score $>2.5$ ) was 8.5 (95\%CI: 3.5-20.7), compared with women having two babies with z-scores $\searrow 0$ to 2.5 . Mothers' cardiovascular mortality was less if only the first baby was very large (HR: 3.4, 95\%CI: 1.8-6.4) or if only the second baby was very large (HR: $1.8,95 \%$ CI: 0.99-3.2).

\section{Discussion}

\section{Main findings}

Mothers whose first baby was very large (gestational-age-adjusted z-score $>2.5$ ) were at increased risk of cardiovascular mortality. This risk was especially high among women whose first two babies were both very large. Women who gave birth to a very large preterm infant were at increased risk of both subsequent diabetes and cardiovascular mortality. With term babies, the association was strong for diabetes, but apparently absent for cardiovascular mortality risk.

We confirm previous findings of increased cardiovascular mortality risk among parents of small birth weights but not larger birth weights, based on absolute weights (Figure 1). 7, 9, 10,12, 13, 18 However, when using gestational-age-standardized birth weights, an increase in maternal cardiovascular mortality emerges for larger birth weights (Figure 2). This association of maternal cardiovascular mortality risk has been suggested by others ${ }^{19,20}$, but results have been conflicting, especially when using absolute birth weights. 7, 13, 18, 21, 22 
Our analysis shows that maternal cardiovascular mortality risk is inflated at the lower end of the absolute birth weight range by the inclusion of preterm births. The use of unadjusted birth weights also distorts the association of maternal cardiovascular mortality after larger offspring. Preterm babies less than 3500 grams can end up in the "lower" birth weight range even if they are large or very large for gestational age. With preterm babies the crucial metric is not smallness in absolute terms, but heaviness for their gestational age. The use of absolute birth weights in previous studies has missed the risk of maternal cardiovascular death associated with preterm babies who are large for gestational age. Babies above a zscore of 1.5 are more frequent among preterm first births (13\%) than term first births (3\%) ( $p$-value difference $<0.0001$ ). The interaction between gestational age and $z$-score for large preterm babies emphasizes the importance of relative growth, and suggests that the association of relatively large birth weights with maternal cardiovascular mortality is more important in preterm than in term infants.

\section{Strengths and limitations}

Strengths of the study include its use of a large national cohort of women with complete prospective registration of exposures and outcomes, with scant missing information. The data provide mortality follow-up for up to 42 years after the first birth, with a median follow-up of 25 years. Additionally, the use of sibling files allows assessment of having repeated large babies, which is associated with even higher maternal risk. The use of standardized birth weight (gestational-age-adjusted birth weight z-scores) becomes crucial when assessing the link between offspring birth weight and maternal cardiovascular mortality.

Limitations of this study include a lack of data on underlying cardiovascular risk factors before and after pregnancy, and information on important covariates such as body mass index and smoking. However, smoking is an established risk factor for having small-forgestational age infants. ${ }^{23}$ It is likely that adjusting for smoking would have further enhanced our risk estimates for larger babies.

\section{Interpretation}

Our analyses show a strong association of large offspring birth weight with maternal cardiovascular mortality when adjusting for gestational age (by z-score). This association was striking with preterm babies but apparently absent with term births. Absolute birth weight, most commonly used in previous studies, masks these risks. Our data confirm previous reports of weak associations between low offspring birth weight and father's cardiovascular mortality.

Previous studies have shown a strong association of preterm delivery with maternal cardiovascular mortality. ${ }^{13,15} \mathrm{We}$ find that this effect is not mediated only through small babies, but is also important for large preterm babies. We are not sure how to interpret the absence of an association of large term babies with maternal cardiovascular mortality (Figure 3). Given that mothers' risk of diabetes in a subsequent pregnancy is equally elevated with relatively large first birth- regardless of gestational age- the lack of an association of large term weights with mothers' cardiovascular mortality risk may not 
convey the complete picture. Longer follow-up of maternal deaths may show a different pattern.

The physiological demands of pregnancy offer an early life "stress-test" that may uncover latent cardiovascular mortality risk in women. Our study shows that gestational age adjusted small and large births are markers of such latent risk, especially with preterm births.

\section{Conclusion}

Women giving birth to a large preterm baby are at increased risk of both diabetes and longterm cardiovascular mortality. The association between increasing offspring birth weight and reduced maternal cardiovascular mortality is not linear across the birth weight range, particularly within preterm births. The birth of a large preterm baby should increase clinical vigilance for onset of diabetes and other possible cardiovascular mortality risk factors.

\section{Supplementary Material}

Refer to Web version on PubMed Central for supplementary material.

\section{Acknowledgments}

Funding: This work was supported by the University of Bergen, the Norwegian Research Council through the University of Bergen and in part by the Intramural Program of the National Institute of Environmental Health Sciences, NIH. The University of Bergen, The Norwegian Research Council and the NIH had no role in the design and conduct of the study; in the collection, analysis, the interpretation of the data; or in the preparation, review, or approval of the manuscript.

The Medical Birth Registry of Norway and the Norwegian Cause of Death registry kindly provided data for the analyses.

\section{References}

1. Rich-Edwards JW, Fraser A, Lawlor DA, Catov JM. Pregnancy characteristics and women's future cardiovascular health: an underused opportunity to improve women's health? Epidemiologic reviews. 2014; 36(1):57-70. [PubMed: 24025350]

2. Mosca L, Hammond G, Mochari-Greenberger H, Towfighi A, Albert MA, et al. American Heart Association Cardiovascular D. Fifteen-year trends in awareness of heart disease in women: results of a 2012 American Heart Association national survey. Circulation. 2013 Mar 19; 127(11):1254-63. e1-29. [PubMed: 23429926]

3. Mosca L, Benjamin EJ, Berra K, Bezanson JL, Dolor RJ, Lloyd-Jones DM, et al. Effectivenessbased guidelines for the prevention of cardiovascular disease in women--2011 update: a guideline from the american heart association. Circulation. 2011 Mar 22; 123(11):1243-62. [PubMed: 21325087]

4. Shaw LJ, Bairey Merz CN, Pepine CJ, Reis SE, Bittner V, Kelsey SF, et al. Insights from the NHLBI-Sponsored Women's Ischemia Syndrome Evaluation (WISE) Study: Part I: gender differences in traditional and novel risk factors, symptom evaluation, and gender-optimized diagnostic strategies. J Am Coll Cardiol. 2006 Feb 7; 47(3 Suppl):S4-S20. [PubMed: 16458170]

5. Christian LM. Physiological reactivity to psychological stress in human pregnancy: current knowledge and future directions. Prog Neurobiol. 2012 Nov; 99(2):106-16. [PubMed: 22800930]

6. Sattar N, Greer IA. Pregnancy complications and maternal cardiovascular risk: opportunities for intervention and screening? BMJ. 2002 Jul 20; 325(7356):157-60. [PubMed: 12130616] 
7. Davey Smith G, Hypponen E, Power C, Lawlor DA. Offspring birth weight and parental mortality: prospective observational study and meta-analysis. Am J Epidemiol. 2007 Jul 15; 166(2):160-9. [PubMed: 17485730]

8. Lawlor DA, Davey Smith G, Whincup P, Wannamethee G, Papacosta O, Dhanjil S, et al. Association between offspring birth weight and atherosclerosis in middle aged men and women: British Regional Heart Study. J Epidemiol Community Health. 2003 Jun; 57(6):462-3. [PubMed: 12775796]

9. Li CY, Chen HF, Sung FC, Chen CC, Lu TH, Yang CH, et al. Offspring birth weight and parental cardiovascular mortality. Int J Epidemiol. 2010 Aug; 39(4):1082-90. [PubMed: 20375103]

10. Smith GC, Pell JP, Walsh D. Pregnancy complications and maternal risk of ischaemic heart disease: a retrospective cohort study of 129,290 births. Lancet. 2001 Jun 23; 357(9273):2002-6. [PubMed: 11438131]

11. Smith GD, Harding S, Rosato M. Relation between infants' birth weight and mothers' mortality: prospective observational study. BMJ. 2000 Mar 25; 320(7238):839-40. [PubMed: 10731177]

12. Smith GD, Sterne J, Tynelius P, Lawlor DA, Rasmussen F. Birth weight of offspring and subsequent cardiovascular mortality of the parents. Epidemiology. $2005 \mathrm{Jul}$; 16(4):563-9. [PubMed: 15951676]

13. Smith GD, Whitley E, Gissler M, Hemminki E. Birth dimensions of offspring, premature birth, and the mortality of mothers. Lancet. 2000 Dec 16; 356(9247):2066-7. [PubMed: 11145495]

14. Irgens LM. The Medical Birth Registry of Norway. Epidemiological research and surveillance throughout 30 years. Acta Obstet Gynecol Scand. 2000 Jun; 79(6):435-9. [PubMed: 10857866]

15. Rich-Edwards JW, Klungsoyr K, Wilcox AJ, Skjaerven R. Duration of pregnancy, even at term, predicts long-term risk of coronary heart disease and stroke mortality in women: a populationbased study. Am J Obstet Gynecol. 2015 Oct; 213(4):518, e1-8. [PubMed: 26070706]

16. Skjaerven R, Wilcox AJ, Klungsoyr K, Irgens LM, Vikse BE, Vatten LJ, et al. Cardiovascular mortality after pre-eclampsia in one child mothers: prospective, population based cohort study. BMJ. 2012; 345:e7677. [PubMed: 23186909]

17. Halland F, Morken NH, DeRoo LA, Klungsoyr K, Wilcox AJ, Skjaerven R. Association of Women's Reproductive History With Long-term Mortality and Effect of Socioeconomic Factors. Obstet Gynecol. 2015 Dec; 126(6):1181-7. [PubMed: 26551179]

18. Davey Smith G, Hart C, Ferrell C, Upton M, Hole D, Hawthorne V, et al. Birth weight of offspring and mortality in the Renfrew and Paisley study: prospective observational study. BMJ. 1997 Nov 8; 315(7117):1189-93. [PubMed: 9393220]

19. Lykke JA, Paidas MJ, Triche EW, Langhoff-Roos J. Fetal growth and later maternal death, cardiovascular disease and diabetes. Acta Obstet Gynecol Scand. 2012 Apr; 91(4):503-10. [PubMed: 22372730]

20. Romundstad PR, Davey Smith G, Nilsen TI, Vatten LJ. Associations of prepregnancy cardiovascular risk factors with the offspring's birth weight. Am J Epidemiol. 2007 Dec 15; 166(12):1359-64. [PubMed: 17978410]

21. Bonamy AK, Parikh NI, Cnattingius S, Ludvigsson JF, Ingelsson E. Birth characteristics and subsequent risks of maternal cardiovascular disease: effects of gestational age and fetal growth. Circulation. 2011 Dec 20; 124(25):2839-46. [PubMed: 22124377]

22. Friedlander Y, Paltiel O, Manor O, Deutsch L, Yanetz R, Calderon-Margalit R, et al. Birthweight of offspring and mortality of parents: the Jerusalem perinatal study cohort. Annals of epidemiology. 2007 Nov; 17(11):914-22. [PubMed: 17855119]

23. McCowan L, Horgan RP. Risk factors for small for gestational age infants. Best Pract Res Clin Obstet Gynaecol. 2009 Dec; 23(6):779-93. [PubMed: 19604726] 


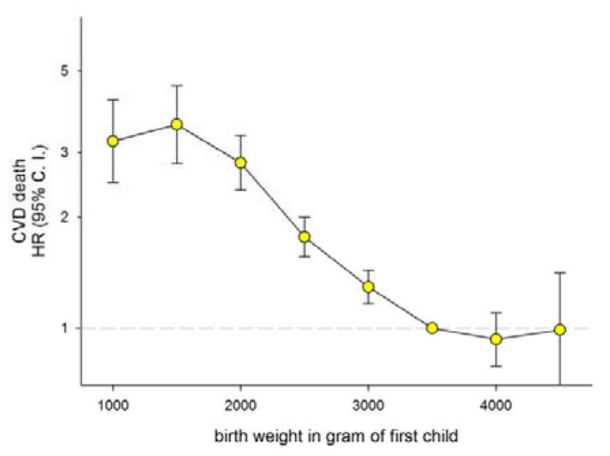

B

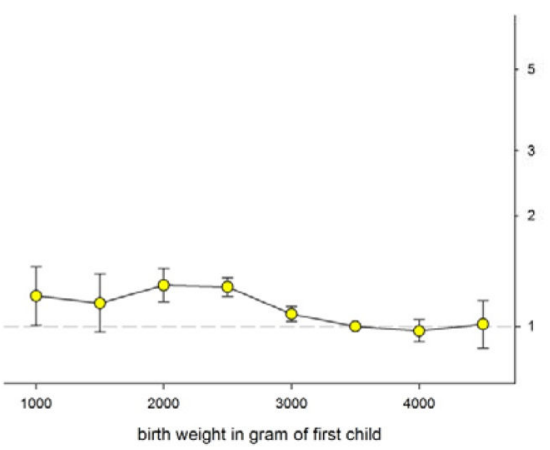

Figure 1.

Maternal (A) and paternal (B) Hazard Ratio (HR) with 95\% Confidence Interval (C. I.) for cardiovascular death (CVD) by offspring birth weight in singleton first births in Norway (1967-2002) with follow-up to 2009. Estimates were adjusted for maternal age and year of birth (711 726 mothers of which 2279 died and 700212 fathers of which 10163 died). 


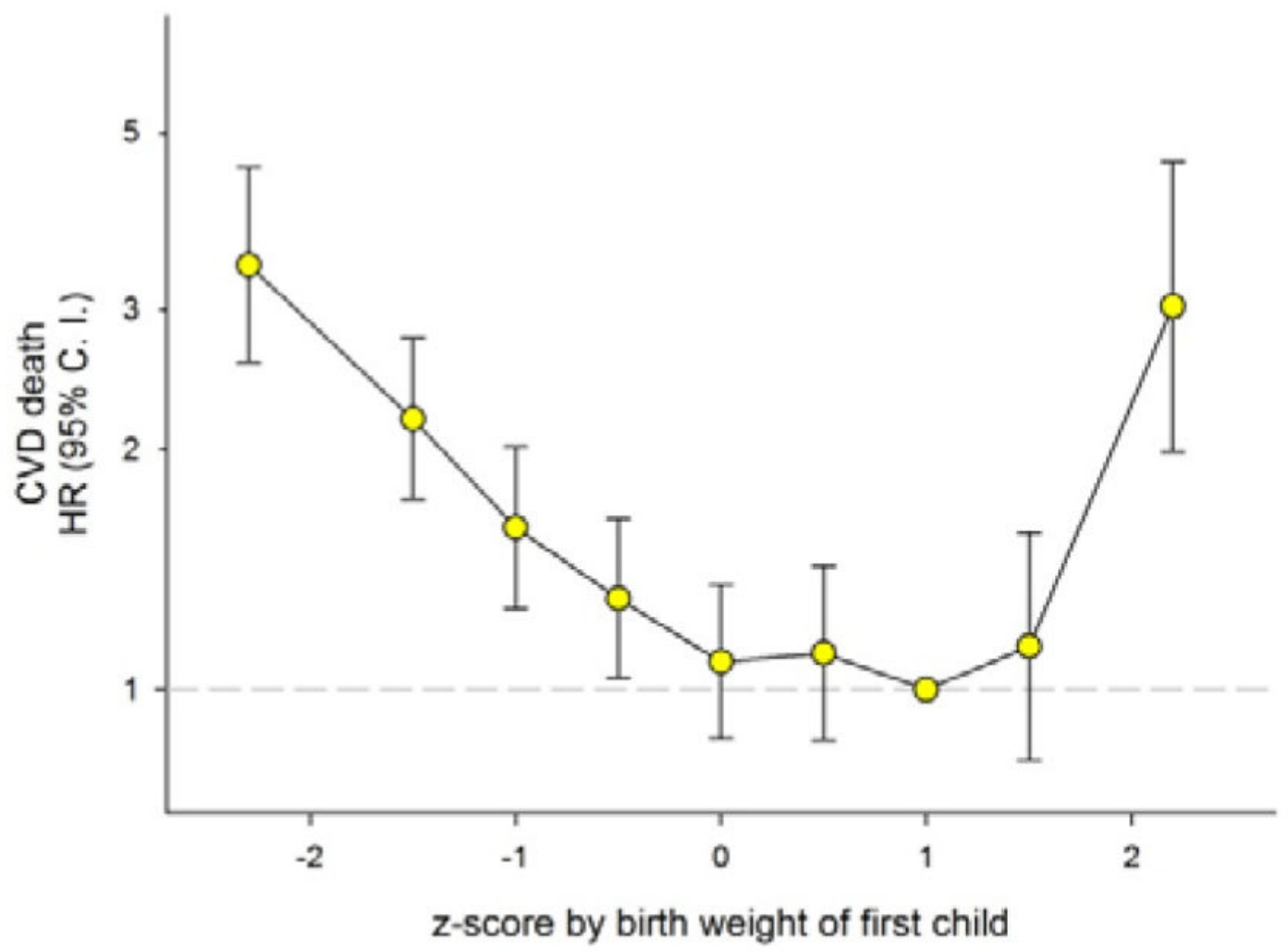

Figure 2.

Maternal Hazard Ratio (HR) with 95\% Confidence Interval (C. I.) for cardiovascular death (CVD) by z-score by birth weight of first born singleton offspring in Norway (1967-2002) with follow-up to 2009 . Estimates were adjusted for maternal age and year of birth and zscore was limited to -4 to +4 (711 726 mothers). 


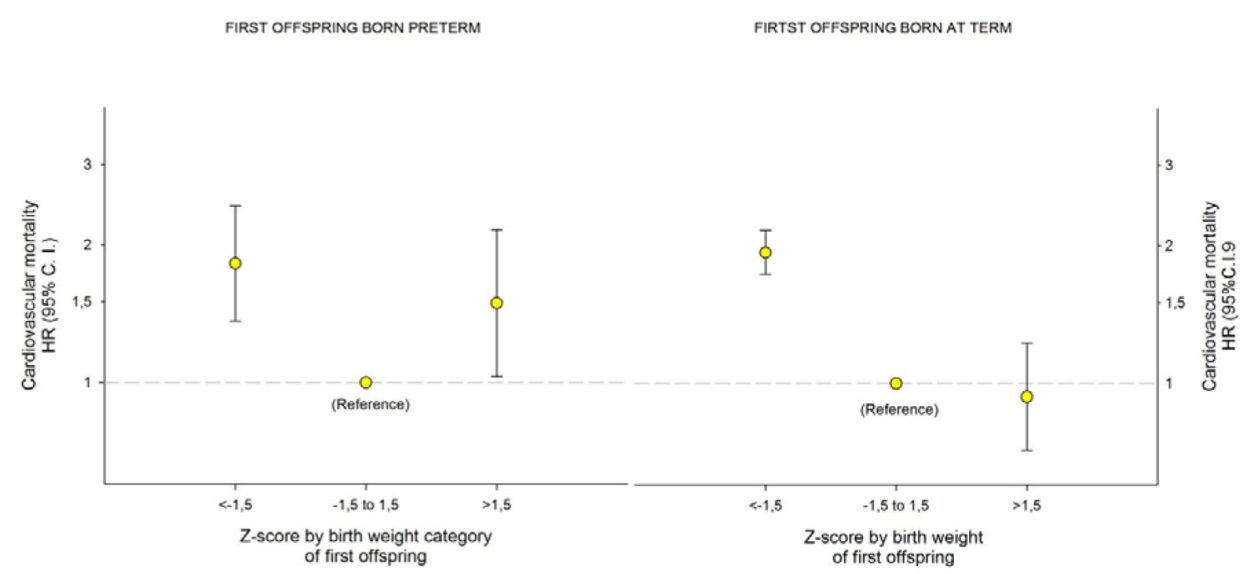

Figure 3.

Maternal Hazard Ratio (HR) with 95\% Confidence Interval (C. I.) for cardiovascular mortality by $\mathrm{z}$-score by birth weight categories $(<-1.5,-1.5$ to 1.5 and $>1.5)$ for first born singleton offspring born preterm (A) and term (B) in Norway 1967 to 2002, with follow-up to 2009. Estimates were adjusted for maternal age and year of birth and z-score was limited to -4 to +4 (43341 and 668385 mothers, respectively). 


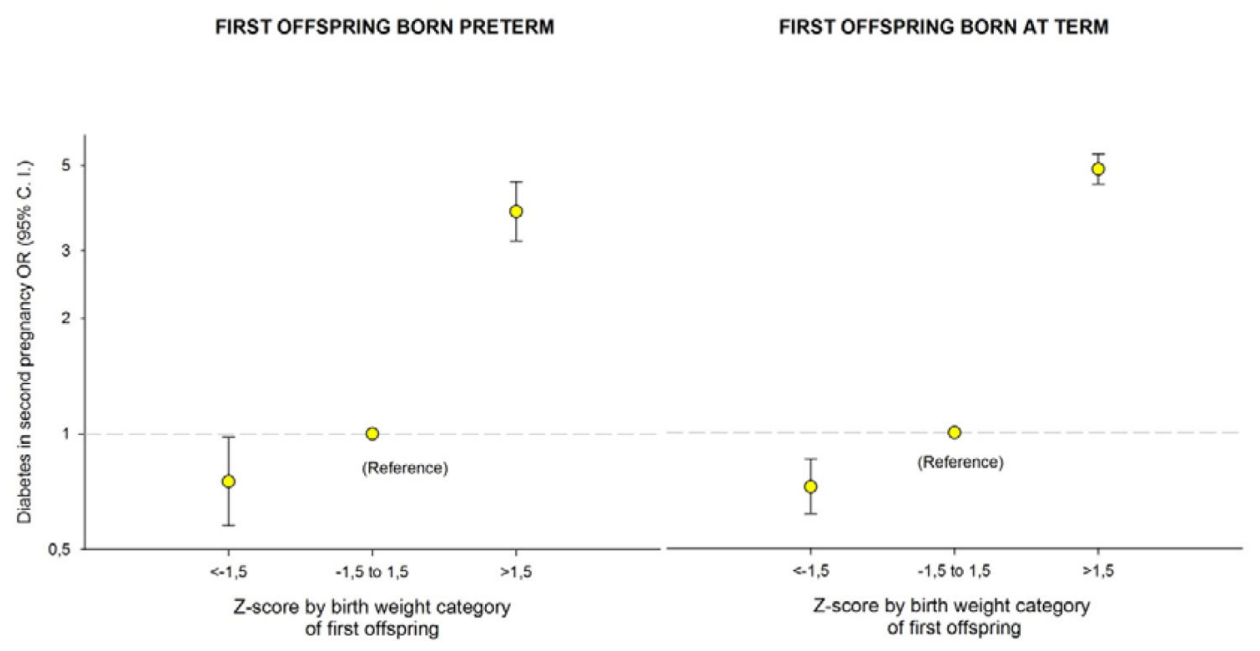

Figure 4.

Odds ratio (OR) for diabetes in the second pregnancy by z-score by birth weight categories $(<-1.5,-1.5$ to 1.5 and $>1.5)$ of singleton first offspring born preterm (A) and term (B) in Norway, 1967 to 2002. Estimates were adjusted for year of birth of the second child and maternal age at second birth; z-score was limited to -4 to +4 (35008 and 567116 mothers, respectively). 


\section{Table 1}

Baseline characteristics of the study sample, Medical Birth Registry of Norway 1967-2002, with follow-up of cardiovascular death (CVD) until 2009.

\begin{tabular}{|c|c|c|}
\hline & & Total $(\%)$ \\
\hline MOTHERS & & 711733 \\
\hline Mothers with missing values & & 7 \\
\hline Mothers in the analyses & & $711726(100)$ \\
\hline Deaths & CVD & $2279(0.32)$ \\
\hline \multirow[t]{5}{*}{ Mothers age (years) } & $<20$ & $102672(14)$ \\
\hline & $20-24$ & $301492(42)$ \\
\hline & $25-29$ & $218262(31)$ \\
\hline & $30-34$ & $69537(10)$ \\
\hline & 235 & $19763(3)$ \\
\hline \multirow[t]{9}{*}{ z-score of firstborn } & -4 to $-2.5(1.5)$ & $10320(1)$ \\
\hline & -2.5 to $-1.5(1)$ & $60500(8.5)$ \\
\hline & -1.5 to $-1(0.5)$ & $86506(12)$ \\
\hline & -0.5 to $-0.5(0.5)$ & $130887(18)$ \\
\hline & -0.5 to $0.5(1)$ & $269665(38)$ \\
\hline & 0.5 to $1(0.5)$ & $80348(11)$ \\
\hline & 1 to $1.5(0.5)$ & $42274(6)$ \\
\hline & 1.5 to $2.5(1)$ & $26418(4)$ \\
\hline & 2.5 to $4(1.5)$ & $4808(0.5)$ \\
\hline \multirow[t]{8}{*}{ Birth weight (gram) of firstborn } & $500-999$ & $7800(1)$ \\
\hline & $1000-1499$ & $6565(1)$ \\
\hline & 1500-1999 & $20043(3)$ \\
\hline & $2000-2499$ & $88420(12)$ \\
\hline & $2500-2999$ & $247028(35)$ \\
\hline & $3000-3499$ & $240511(34)$ \\
\hline & $3500-3999$ & $85631(12)$ \\
\hline & $\geq 4000$ & $15728(2)$ \\
\hline FATHERS & & 711733 \\
\hline Fathers with missing values & & 11521 \\
\hline Fathers in the analyses & & $700212(100)$ \\
\hline Deaths & CVD & $10163(1.45)$ \\
\hline \multirow[t]{3}{*}{ Fathers age (years) } & $<20$ & $23098(3)$ \\
\hline & $20-24$ & $217741(32)$ \\
\hline & $25-29$ & 268459 \\
\hline
\end{tabular}




\begin{tabular}{|c|c|c|c|}
\hline \multirow{4}{*}{ 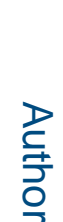 } & \multicolumn{3}{|r|}{ Total (\%) } \\
\hline & & $30-34$ & $127156(18)$ \\
\hline & & 235 & $63758(9)$ \\
\hline & \multirow[t]{9}{*}{ z-score of firstborn } & -4 to $-2.5(1.5)$ & $9839(1.4)$ \\
\hline 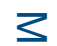 & & -2.5 to $-1.5(1)$ & $59062(8.4)$ \\
\hline פ & & -1.5 to $-1(0.5)$ & $84867(12.1)$ \\
\hline$\frac{c}{\omega}$ & & -0.5 to $-0.5(0.5)$ & $128845(18.4)$ \\
\hline 을. & & -0.5 to 0.5 (1) & 265925 (38) \\
\hline & & 0.5 to $1(0.5)$ & $79311(11)$ \\
\hline & & 1 to $1.5(0.5)$ & $41686(6)$ \\
\hline & & 1.5 to $2.5(1)$ & $26001(4)$ \\
\hline & & 2.5 to $4(1.5)$ & $4676(0.7)$ \\
\hline & \multirow[t]{8}{*}{ Birth weight (gram) of firstborn } & 500-999 & $6601(1)$ \\
\hline D & & $1000-1499$ & $6277(1)$ \\
\hline$\overline{2}$ & & $1500-1999$ & 19545 (3) \\
\hline & & $2000-2499$ & $86701(12)$ \\
\hline న & & 2500-2999 & $243310(35)$ \\
\hline$\stackrel{5}{2}$ & & $3000-3499$ & $235543(34)$ \\
\hline 气 & & $3500-3999$ & $86678(12)$ \\
\hline$\overline{\bar{\theta}}$ & & $\geq 4000$ & $15557(2)$ \\
\hline
\end{tabular}




\section{Table 2}

Hazard ratio (HR) with 95\% Confidence Interval (CI) for parental cardiovascular death by unit change in birth weight (per 500 gram) of first singleton offspring in Norway 1967-2002 with follow-up until 2009. Estimates were adjusted for year of birth and parental age.

\begin{tabular}{c|c|c|c|c}
\hline First offspring birth weight & \multicolumn{2}{|c|}{ Mothers (n= 711 726) } & Fathers (n= 700 212) \\
\hline & HR (95\% CI) & p for trend & HR (95\% CI) & p for trend \\
\hline \multirow{2}{*}{500 to 3500 gram } & $0.75(0.71-0.78)$ & $<0.0001$ & $0.94(0.91-0.96)$ & $<0.0001$ \\
23500 gram & $0.96(0.85-1.10)$ & 0.57 & $0.99(0.94-1.05)$ & 0.70 \\
\hline
\end{tabular}




\section{Table 3}

Hazard ratio (HR) with 95\% confidence interval (CI) for maternal cardiovascular death by first and second sibling z-score by birth weight, the Medical Birth Registry of Norway, 1967 to 2002 on 158772 sib pairs with $z$-score $>=0$ to $<4$. Estimates were adjusted for maternal age and year of birth of the first sibling, with followup until 2009.

\begin{tabular}{c|c|c|c}
\hline Z-score by birth weight for sibling 1 and 2 & Sibling pairs (n) & Maternal deaths per 1000 & HR (95\% CI) \\
\hline Sibling 1: >2.5 and Sibling 2: >2.5 & 529 & 9.45 & $8.5(3.5-20.7)$ \\
Sibling 1: $>2.5$ and Sibling 2: $\searrow$ to 2.5 & 2422 & 4.12 & $3.4(1.8-6.4)$ \\
Sibling 1: $\searrow 0$ to 2.5 and Sibling 2: >2.5 & 5418 & 2.21 & $1.8(0.99-3.2)$ \\
Sibling 1: $\searrow$ to 2.5 and Sibling 2: $\searrow$ ) to 2.5 & 150403 & 1.41 & 1.0 (Reference) \\
\hline
\end{tabular}

